\title{
Incidence of metastatic breast cancer in an Australian population-based cohort of women with non-metastatic breast cancer at diagnosis
}

\section{Sarah J Lord MBBS, MS, FRACGP Epidemiologist \\ M Luke Marinovich BA,MPH \\ Jillian A Patterson BSc, MBiostats,
Biostatistician \\ Nicholas Wilcken MBBS, PhD, FRACP, Associate Professor Medical Oncology \\ Belinda E Kiely MBBS, FRACP PhDCandidate \\ Val Gebsk BA, MStats, FRANZCR(Hons) Professor, Biostatistics and Research Methodology \\ Sally Crossing AM, BEC, \\ Consumer Advocate \\ David M Roder AM, MPH, DDSC Professor of \\ Cancer Epidemiology ${ }^{6}$ \\ Melina Gattellari PhD, MPH, BSc(Psychol) Senior Lecturer \\ Nehmat Houssam MBBS, PhD, FAFPHM Associate Professor and Principal Research Fellow ${ }^{2}$}

1 National Health and Medical Research Council Clinical Trials Centre

University of Sydney, Sydney, NSW.

2The Screening and Test Evaluation Program,
School of Public Health,

University of Sydney, Sydney, NSW.

3 NSW Ministry of Health Sydney, NSW.

4 Westmead Hospital

University of Sydney, Sydney, NSW.

5 Cancer Voices NSW Sydney, NSW. 6 University of South Australia Adelaide, SA.

7 School of Public Health and Community Medicine, University of

New South Wales,

Sydney, NSW.

slord@ctc.usyd.edu.au

MJA 2012; 196: 688-692

doi: 10.5694/mjal2.10026

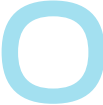

ne of the major concerns for women diagnosed with early breast cancer (BC) is their risk of developing metastatic cancer (MBC). ${ }^{1}$ Information on the risk of and prognosis for patients with MBC is important to help patients make decisions about treatment and plan for the future. It is also important for health service planning and identifying research priorities. Currently, cancer registries do not routinely report this information. Consumer groups in Australia $^{2}$ and internationally ${ }^{3}$ have urged for improved data collection on cancer recurrence and reporting.

Over the past 20 years, cancer registries have documented continued improvements in survival among patients with BC. ${ }^{4}$ These survival gains have been attributed to advances in treatment, particularly systemic adjuvant therapies after pivotal trials, and to a lesser extent, BC screening programs. ${ }^{5,6}$ However, the gains for women with early $\mathrm{BC}$ in terms of their risk of developing $\mathrm{MBC}$ have not been well documented. Earlier studies may no longer be relevant to contemporary populations. At present, clinicians generally rely on published clinical trials for information on these outcomes, but the extent to which trial data can be applied to the general population of women with $\mathrm{BC}$ is not known.

We aimed to report Australian population-based estimates of the incidence of MBC for women initially diagnosed with non-metastatic BC. We were particularly interested in the experiences of women aged 70 years and older, and of women from regional and remote areas, two populations not well represented in clinical trials.

\begin{abstract}
Objectives: To estimate the incidence of metastatic breast cancer (MBC) in Australian women with an initial diagnosis of non-metastatic breast cancer.

Design, setting and participants: A population-based cohort study of all women with non-metastatic breast cancer registered on the New South Wales Central Cancer Register (CCR) in 2001 and 2002 who received care in a NSW hospital.

Main outcome measures: 5-year cumulative incidence of MBC; prognostic factors for MBC.

Results: MBC was recorded within 5 years in 218 of 4137 women with localised node-negative disease (5-year cumulative incidence, 5.3\%; $95 \% \mathrm{Cl}, 4.6 \%$ $6.0 \%$ ); and 455 of 2507 women with regional disease (5-year cumulative incidence, 18.1\%; 95\% Cl, 16.7\%-19.7\%). The hazard rate for developing MBC was highest in the second year after the initial diagnosis of breast cancer. Determinants of increased risk of MBC were regional disease at diagnosis, age less than 50 years and living in an area of lower socio-economic status.

Conclusions: Our Australian population-based estimates are valuable when communicating average MBC risks to patients and planning clinical services and trials. Women with node-negative disease have a low risk of developing MBC, consistent with outcomes of adjuvant clinical trials. Regional disease at diagnosis remains an important prognostic factor.
\end{abstract}

\section{Methods}

All women aged 18 years and older diagnosed with invasive (not intraductal) localised or regional BC between 1 January 2001 and 31 December 2002 and recorded on the New South Wales Central Cancer Registry (CCR) were included. Patients were excluded if the extent of disease spread at diagnosis was recorded as distant or unknown, or if they had no hospital care recorded on the NSW Admitted Patient Data Collection (APDC).

\section{Data sources}

The CCR receives notification of all new cancer cases diagnosed in NSW residents from public and private hospitals, radiation oncology departments, nursing homes, pathology laboratories, outpatient departments and day-procedure centres as a statutory requirement. ${ }^{7}$ A summary classification is used to classify degree of cancer spread as: localised (node-negative tumour confined to breast tissue); regional (spread to regional lymph nodes or adjacent tissues, includes locally advanced disease); distant (spread beyond the breast, adjacent tissues and regional lymph nodes); or unknown. Women with $\mathrm{MBC}$ recorded within 120 days of the date of their initial diagnosis with primary breast cancer are classified as having distant disease at diagnosis.

Dates (month, year) of birth, BC diagnosis and $\mathrm{MBC}$ diagnosis for each patient were extracted from the CCR up to 31 December 2007, together with information on the degree of spread at diagnosis, tumour type (International classification of diseases for oncology, 3rd edition morphology codes), other primary neoplasms, country of birth, and local government area of residence at $\mathrm{BC}$ diagnosis. We used local government area to classify area of residence 
1 Baseline characteristics of women with non-metastatic breast cancer (BC), by degree of spread at initial diagnosis, New South Wales Central Cancer Register, 2001 and 2002

\begin{tabular}{|c|c|c|c|c|}
\hline \multirow[b]{2}{*}{ Characteristic } & \multirow[b]{2}{*}{ All women } & \multicolumn{2}{|c|}{ Women with } & \multirow[b]{2}{*}{ P* } \\
\hline & & $\begin{array}{l}\text { Localised } \\
\text { spread }\end{array}$ & $\begin{array}{c}\text { Regional } \\
\text { spread }\end{array}$ & \\
\hline & $6644(100 \%)$ & $4137(62 \%)$ & $2507(38 \%)$ & \\
\hline \multicolumn{5}{|l|}{ Age at diagnosis } \\
\hline$<50$ years & $1645(25 \%)$ & $856(21 \%)$ & 789 (31\%) & \\
\hline $50-59$ years & $1772(27 \%)$ & $1081(26 \%)$ & $691(28 \%)$ & \\
\hline $60-69$ years & $1493(22 \%)$ & $1000(24 \%)$ & $493(20 \%)$ & \\
\hline$\geqslant 70$ years & $1734(26 \%)$ & $1200(29 \%)$ & $534(21 \%)$ & $<0.0001$ \\
\hline \multicolumn{5}{|l|}{ Morphology of primary BC } \\
\hline Invasive ductal & $5058(76 \%)$ & 3115 (75\%) & $1943(78 \%)$ & \\
\hline Lobular & $840(13 \%)$ & $482(12 \%)$ & $358(14 \%)$ & \\
\hline Other & $746(11 \%)$ & $540(13 \%)$ & $206(8 \%)$ & $<0.0001$ \\
\hline \multicolumn{5}{|c|}{ Other primary cancer before $\mathrm{BC}$} \\
\hline No & $6332(95 \%)$ & 3922 (95\%) & $2410(96 \%)$ & \\
\hline Yes & $312(5 \%)$ & $215(5 \%)$ & $97(4 \%)$ & 0.01 \\
\hline \multicolumn{5}{|l|}{ Area of residence } \\
\hline Major city & $4876(73 \%)$ & $2998(72 \%)$ & $1878(75 \%)$ & \\
\hline Regional & $1743(26 \%)$ & $1124(27 \%)$ & $619(25 \%)$ & \\
\hline Remote & $25(<1 \%)$ & $15(<1 \%)$ & $10(<1 \%)$ & 0.08 \\
\hline \multicolumn{5}{|c|}{ Socioeconomic status (quintiles) } \\
\hline 1 & $1278(19 \%)$ & $804(19 \%)$ & $474(19 \%)$ & \\
\hline 2 & 1175 (18\%) & $723(17 \%)$ & $452(18 \%)$ & \\
\hline 3 & $1333(20 \%)$ & $833(20 \%)$ & $500(20 \%)$ & \\
\hline 4 & $1245(19 \%)$ & $774(19 \%)$ & $471(19 \%)$ & \\
\hline 5 & $1613(24 \%)$ & $1004(24 \%)$ & $610(24 \%)$ & 0.97 \\
\hline \multicolumn{5}{|l|}{ Country of birth } \\
\hline Australia/New Zealand & $4531(68 \%)$ & $2823(68 \%)$ & $1708(68 \%)$ & \\
\hline Other & 2113 (32\%) & $1314(32 \%)$ & 799 (32\%) & 0.93 \\
\hline
\end{tabular}

as major cities or regional/remote using the Accessibility/Remoteness Index of Australia classification ${ }^{8}$ and socioeconomic status using the Socio-economic Indexes for Areas classification. ${ }^{9}$

The APDC codes the principal diagnosis, additional diagnoses and procedures for all episodes of care, including day-only admissions, from NSW hospitals, private day-procedure centres and public nursing homes, using the International classification of disease and related health problems, version 10, Australianmodification (ICD-10 AM) coding system. It does not record prescribed medications.

Health record linkage was undertaken by the Centre for Health Record Linkage (CHeReL) to obtain information about all episodes of care recorded on the NSW APDC for the study population between 1 January 2001 and 31 December 2007. CHeReL constructs a master linkage key to link health records from different databases using probabilistic record linkage software with quality assurance procedures designed to achieve fewer than $0.5 \%$ false positive matches and fewer than $0.5 \%$ false negative matches where full identifiers are available. ${ }^{10}$ For our study, CHeReL calculated a false positive error rate of $0.3 \%$.

\section{Outcomes}

Patients were classified as having MBC if they had a CCR record of $\mathrm{MBC}$ within 5 years of their initial diagnosis of BC. To classify MBC sites, we used ICD10AM diagnosis codes for site of secondary malignant neoplasms from the first "index" episode of care recorded on the APDC after the initial diagnosis of BC. For patients having a second non-breast primary cancer, we only extracted this information if a matching CCR record was available to verify $\mathrm{MBC}$ status for that episode of care.

\section{Statistical analyses}

Kaplan-Meier analysis was used to report time to $\mathrm{MBC}$, and the 5-year cumulative incidence of MBC was calculated as the proportion of women diagnosed as not having $\mathrm{MBC}$ who had $\mathrm{MBC}$ recorded within 5 years. Time to MBC was defined as the time from the diagnosis of $\mathrm{BC}$ to the date of the first record of $\mathrm{MBC}$ on the CCR or the APDC, whichever occurred earliest. For patients who also had a second non-breast primary cancer, we used only the date of the first CCR record of MBC because MBC status could not be determined from an APDC diagnosis of secondary cancer. The log-rank test was used to test for differences in time to MBC by age group and degree of spread. The annual MBC hazard rate was calculated by degree of spread.

Cox proportional hazards regression was used to identify factors associated with MBC-free survival. The model was stratified by the presence of other primary cancers at diagnosis to account for the difference in underlying risk between the groups. The final model was developed using backwards elimination, starting with all covariates and removing the least significant variable until only variables significant at $\alpha=0.05$ remained.

All analyses were performed using SAS, version 9.2 (SAS Institute, Cary, NC, USA).

\section{Ethics approval}

This study was approved by the NSW Population and Health Services Research Committee.

\section{Results}

During 2001 and 2002, 8142 women had their diagnoses of invasive BC recorded on the CCR. After excluding women with MBC at diagnosis (546), unknown degree of spread (791) or no hospital care recorded in NSW (161), 6644 patients were included in the study. Of these, 4137 had localised BC, and 2507 had regional BC. Their median age was 59 years (interquartile range [IQR], 50-70 years). Women's age, tumour histology and the presence of other non-breast primary cancer sites varied by degree of spread at diagnosis (Box 1). 


\section{Cumulative incidence of metastatic breast cancer and annual hazard rate by} degree of spread at initial diagnosis

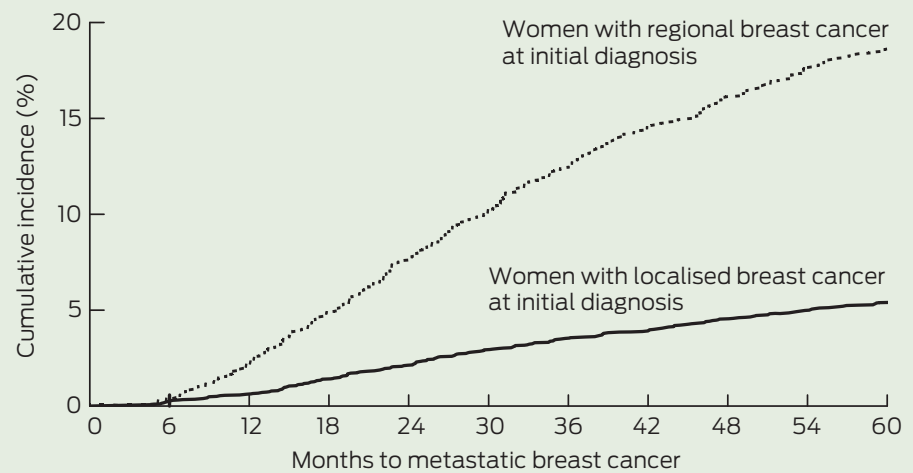

Number at risk

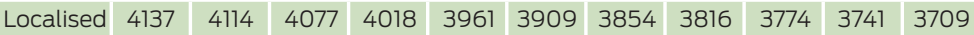

\begin{tabular}{|l|l|l|l|l|l|l|l|l|l|l|l|} 
Regional & 2507 & 2489 & 2425 & 2339 & 2253 & 2173 & 2102 & 2047 & 1996 & 1951 & 1919 \\
\hline
\end{tabular}

Annual metastatic breast cancer hazard rate

\begin{tabular}{|l|c|c|c|c|c|}
\hline & $<12$ months & $12-23$ months & $24-35$ months & $36-47$ months & $48-60$ months \\
\hline Localised & $0.6 \%$ & $1.5 \%$ & $1.4 \%$ & $1.0 \%$ & $0.9 \%$ \\
\hline Regional & $2.3 \%$ & $5.4 \%$ & $5.1 \%$ & $3.7 \%$ & $2.9 \%$ \\
\hline
\end{tabular}

\section{5-year cumulative incidence of} metastatic breast cancer

A total of 673 patients had MBC recorded within 5 years of being diagnosed with BC, representing 218 women with localised BC (5.3\%; 95\% CI, $4.6 \%-6.0 \%)$; and 455 women with regional $\mathrm{BC}(18.1 \%$; $95 \% \mathrm{CI}$,
$16.7 \%-19.7 \%)$. The difference in the cumulative incidence of $\mathrm{MBC}$ by degree of spread at diagnosis was statistically significant (log-rank $P<0.0001$; Box 2). After stratifying patients by degree of spread at diagnosis, we found that the annual hazard rate of $\mathrm{MBC}$ was highest in the
3 Univariable and multivariable analyses showing factors associated with metastatic breast cancer being recorded within 5 years among 6644 women

\begin{tabular}{|c|c|c|c|c|c|c|c|}
\hline \multirow[b]{2}{*}{ Characteristic } & \multirow{2}{*}{$\begin{array}{l}\text { MBC*/total } \\
\text { in each } \\
\text { category }\end{array}$} & \multicolumn{3}{|c|}{ Univariable analysis } & \multicolumn{3}{|c|}{ Multivariable analysis } \\
\hline & & $\mathrm{HR}$ & $95 \% \mathrm{Cl}$ & $P$ & HR & $95 \% \mathrm{Cl}$ & $P$ \\
\hline \multicolumn{8}{|l|}{ Degree of spread } \\
\hline Localised & $218 / 4137$ & 1.00 & & & 1.00 & & \\
\hline Regional & $455 / 2507$ & 3.65 & $(3.13-4.25)$ & $<0.0001$ & 3.55 & $(3.04-4.14)$ & $<0.0001$ \\
\hline \multicolumn{8}{|l|}{ Age } \\
\hline$<50$ years & $238 / 1645$ & 1.00 & & & 1.00 & & \\
\hline 50-69 years & $285 / 3265$ & 0.61 & $(0.51-0.72)$ & & 0.70 & $(0.59-0.82)$ & \\
\hline$\geqslant 70$ years & $150 / 1734$ & 0.64 & $(0.52-0.78)$ & $<0.0001$ & 0.80 & $(0.65-0.97)$ & $<0.0001$ \\
\hline \multicolumn{8}{|l|}{ Tumour type } \\
\hline Ductal & $544 / 5058$ & 1.00 & & & & & \\
\hline Lobular/mixed & $75 / 840$ & 0.80 & $(0.64-1.01)$ & & & & \\
\hline Other & $54 / 746$ & 0.67 & $(0.51-0.87)$ & 0.004 & & & \\
\hline \multicolumn{8}{|l|}{ Area of residence } \\
\hline Major cities & $488 / 4876$ & 0.96 & $(0.82-1.13)$ & & & & \\
\hline Regional/remote & $185 / 1768$ & 1.00 & & 0.61 & & & \\
\hline \multicolumn{8}{|c|}{ Socioeconomic status } \\
\hline Quintile $5^{\dagger}$ & $124 / 1613$ & 1.00 & & & 1.00 & & \\
\hline Quintiles 2-4 $4^{\ddagger}$ & $409 / 3753$ & 1.35 & $(1.12-1.63)$ & & 1.35 & $(1.12-1.63)$ & \\
\hline Quintile $1^{5}$ & $140 / 1278$ & 1.39 & $(1.11-1.74)$ & 0.004 & 1.42 & $(1.13-1.79)$ & 0.003 \\
\hline \multicolumn{8}{|l|}{ Country of birth } \\
\hline Australia/NZ & 479/4531 & 1.17 & $(1.00-1.38)$ & & & & \\
\hline Other & 194/2113 & 1.00 & & 0.05 & & & \\
\hline
\end{tabular}

$\mathrm{HR}=$ hazard ratio. $\mathrm{MBC}=$ metastatic breast cancer. $\mathrm{NZ}=\mathrm{New}$ Zealand

* MBC was defined as an MBC event recorded on NSW Central Cancer Register within 5 years of initial diagnosis date.

$\uparrow$ Least disadvantaged. ‡ Middle disadvantage. § Most disadvantaged. second year after diagnosis for women with both localised and regional BC (Box 2). This pattern was observed consistently across each age group (data not shown).

In multivariable analysis, $\mathrm{MBC}$ risk was statistically significantly higher for women younger than 50 years at $\mathrm{BC}$ diagnosis relative to those aged 50-69 years or 70 years and older. $\mathrm{MBC}$ risk was also higher for women with regional versus localised $\mathrm{BC}$, and for women from more socioeconomically disadvantaged areas compared with women from the least disadvantaged areas (Box 3).

\section{Site of metastatic breast cancer}

Of the 673 patients with MBC, 599 (89\%) also had an APDC diagnosis code for secondary cancer, which allowed identification of first MBC anatomical site. The most common site was bone, recorded for 276 patients $(46 \%)$; lung/pleura, 224 (37\%); liver, 194 (32\%); and brain, 78 $(13 \%)$. Two-thirds of patients (403; $67 \%$ ) had at least one visceral site of MBC at their index episode of care. A single MBC site was recorded for 369 (62\%) patients at the index episode of care. Of these, 129 (35\%) had boneonly disease, and a smaller proportion had liver-only, lung-only or brainonly disease (Box 4).

\section{Discussion}

In this Australian population-based cohort of 6644 women with non-metastatic BC, we found that about one in 20 women with localised node-negative disease and one in 6 women with regional disease at initial diagnosis developed MBC within 5 years. Clinicians can use these estimates to inform women with $\mathrm{BC}$ about the average risks of developing $\mathrm{MBC}$.

Internationally, very few population-based studies have examined $\mathrm{MBC}$ incidence in patients with nonmetastatic BC at initial diagnosis. European researchers recently reported a 5-year MBC risk of $10 \%$ for 18592 patients with no distant metastases at diagnosis on the Munich Cancer Register between 1995 and 2003. ${ }^{11}$ These results are consistent with our findings of a 5-year MBC risk of $10 \%$ for the combined cohort of Australian patients with localised and 
regional disease. Our findings also show that, despite the known importance of underlying tumour biology in defining cancer prognosis, spread of disease at diagnosis (localised versus regional) remains an important prognostic factor in BC.

Although clinical trials can provide data to estimate the incidence of MBC for selected BC populations, it is unclear to what extent trial estimates, which are drawn from patients receiving care from participating institutions who meet trial eligibility criteria, apply to the general population with cancer. In the United States, it is documented that older individuals, those with low socioeconomic status, and those living in areas with a lower number of oncology specialists and hospital programs are underrepresented in cancer trials relative to their cancer burden. ${ }^{12}$ In examining whether these factors are also associated with MBC risk, we found a statistically significant association between socioeconomic status and MBC risk, but did not observe an association for women aged 70 years and older versus those aged 50-70 years, or for those living within versus outside a major city. The association between living in more socioeconomically disadvantaged areas and an increased risk of $\mathrm{MBC}$ is consistent with Australian evidence of reduced breast cancer survival for these patient groups. ${ }^{13}$ This finding is worthy of further study, and may have important implications for health service providers and health funding policymakers. The higher risk of MBC observed for patients aged less than 50 years compared with older age groups may be partly attributed to more aggressive tumour biology in younger women. ${ }^{14}$

Overall, we did not find evidence that the risk of $\mathrm{MBC}$ for women with node-negative $B C$ in the general population differed substantially from that of trial populations. Our estimate of a 5-year MBC cumulative incidence of $5.3 \%$ is at least as favourable as outcomes reported in adjuvant systemic therapy trials in node-negative populations that informed practice in 2001 (5\%-8\% of trial patients had $\mathrm{MBC}$ recorded as a first event with an average $5-6$ years follow-up). ${ }^{15,16}$ It is more difficult to draw comparisons between our results for patients with regional $\mathrm{BC}$ at diagnosis and trialbased estimates because, in our study, regional $\mathrm{BC}$ includes nodal metastases with the primary tumour confined to the breast as well as locally advanced BC, which confers a relatively poorer prognosis. In contrast, most trials are designed to assess interventions in one or other of these subgroups. Despite this, the 5-year MBC incidence of $18.1 \%$ that we observed for patients with regional BC falls within the upper range of $\mathrm{MBC}$ risk observed in adjuvant chemotherapy trials conducted in node-positive populations $(14 \%-20 \%$ for different treatment arms). ${ }^{17-19}$

We found the annual rate of MBC notification peaks in the second year after diagnosis, and then decreases over time for both patients with localised and regional $\mathrm{BC}$, and across age groups. These findings are consistent with earlier studies investigating the risk of any recurrence conducted in both trial ${ }^{20}$ and non-trial ${ }^{21}$ populations, with the highest hazard rate for early MBC being observed in women with more aggressive disease subtypes. This information may provide some reassurance for women who completed their primary BC treatment more than 2 years ago and remain recurrence free.

Our study cohort was diagnosed with BC in 2001 and 2002, so would have had access to current standard breast screening protocols and most contemporary adjuvant systemic therapies, except trastuzumab and taxanes; both of which only received broad listing for early BC on the Pharmaceutical Benefits Scheme in 2006. The National Breast Cancer Audit conducted during the period of our study indicates that tamoxifen was widely used for women with oestrogen receptor-positive $\mathrm{BC}$; systemic adjuvant chemotherapy was used for $63 \%$ of pre-menopausal women and $28 \%$ of post-menopausal women (including $83 \%$ of oestrogen receptornegative, node-positive postmenopausal cases).22 Given that the availability and use of effective systemic therapies has increased over the past decade, we anticipate that the incidence of MBC among women with a more recent $B C$ diagnosis, especially those with $\mathrm{BC}$ in which the human
4 Anatomical site of metastatic breast cancer from hospital ICD-10 AM diagnosis codes in the 599 women who had an Admitted Patient Data Collection diagnosis code for secondary cancer

\begin{tabular}{lcc} 
& \multicolumn{2}{c}{$\begin{array}{c}\text { Women at episode of hospital care } \\
\text { for MBC }\end{array}$} \\
\cline { 2 - 3 } Site of MBC & $\begin{array}{c}\text { First } \\
\text { episode }\end{array}$ & $\begin{array}{c}\text { All episodes } \\
\text { within 5 years }\end{array}$ \\
\hline Bone & $276(46 \%)$ & $366(61 \%)$ \\
Liver & $194(32 \%)$ & $292(49 \%)$ \\
Lung & $168(28 \%)$ & $244(41 \%)$ \\
Brain & $78(13 \%)$ & $167(28 \%)$ \\
Pleura & $73(12 \%)$ & $114(19 \%)$ \\
Other & $136(23 \%)$ & $213(36 \%)$ \\
Any liver/lung/ brain/pleura & $393(66 \%)$ & $489(82 \%)$ \\
Single site only & $369(62 \%)$ & $183(31 \%)$ \\
Bone & $129(22 \%)$ & $70(12 \%)$ \\
Soft tissue & $50(8 \%)$ & $6(1 \%)$ \\
Liver & $53(9 \%)$ & $36(6 \%)$ \\
Lung & $54(9 \%)$ & $21(4 \%)$ \\
Brain & $36(6 \%)$ & $21(4 \%)$ \\
\hline
\end{tabular}

$\mathrm{MBC}=$ metastatic breast cancer, $\mathrm{ICD}-10 \mathrm{AM}=$ International classification of disease and related health problems, version 10, Australian-modification.

epidermal growth factor receptor 2 protein is over-expressed (HER2-positive disease), may be even lower than our study estimates.

The strengths of our study are the size of the study population and the degree to which it is representative of the general Australian population of women with a diagnosis of non-metastatic BC. Our study shows the feasibility of using routinely collected data from the CCR and APDC to report rates of distant cancer recurrence in a timely fashion. Over time, these analyses can be extended to include longer-term data from the study cohort to assess 10-year MBC risk, and to include more recent cohorts.

Our methods have two main limitations. First, although the accuracy of the CCR in recording primary cancer events and of the hospital database in coding cancer diagnoses and procedures have both been documented to be high, ${ }^{23,24}$ the completeness and accuracy of cancer recurrence records has not been formally investigated. Further research is required to determine the proportion of MBC cases that are not notified to the CCR. There would be no notification for patients who had a clinical diagnosis of $\mathrm{MBC}$ made in an outpatient setting without a biopsy or any diagnostic or therapeutic hospital service. Some women with MBC will receive outpatientbased care for a number of years 
before requiring hospital admission for a treatment complication or disease event, and many will not have had a biopsy to confirm their diagnosis. These individuals would not have been recorded as having $\mathrm{MBC}$ in our study, so it is possible that the true average 5 -year incidence of $\mathrm{MBC}$ is higher than our study estimate. Second, these administrative datasets do not provide information about prognostic factors, such as receptor status or treatments received, to develop risk estimates for specific patient groups. Cancer Institute NSW has recently implemented a clinical cancer register to help overcome these limitations.

Overall, our population-level estimates provide an important supplement to existing clinical trial data to help doctors answer questions about average $\mathrm{MBC}$ risk for the many women with $\mathrm{BC}$ in the community who may not be represented in clinical trials. This information can also inform cancer services planning, provide contemporary estimates of $\mathrm{MBC}$ risk to researchers planning clinical trials of treatments for early BC, and suggest priorities for research, such as investigating and improving MBC outcomes for socioeconomically disadvantaged women. Our finding that women with node-negative $\mathrm{BC}$ have a low risk of developing $\mathrm{MBC}$ is reassuring, suggesting that treatment advances demonstrated in clinical trials of adjuvant therapy are delivered to the general population of women with BC.

Acknowledgements: We thank the NSW Central Cance Registry and the NSW Department of Health for providing data for this study, and the Centre for Health Record Linkage for undertaking the data linkage. We are grateful to Narelle Grayson and Maria Arcorace from the NSW Central Cancer Registry for their advice on the methods and interpretation of cancer registry data. This study was supported through an Australian National Health and Medical Research Council Project Grant (No 633223).

Competing interests: No relevant disclosures.
Received 5 Jan 2012, accepted 1 May 2012.

1 Mehnert A, Berg P, Henrich G, Herschbach P. Fear of cancer progression and cancer-related intrusive cognitions in breast cancer survivors. Psychooncology 2009; 18: 1273-1280.

2 Breast Cancer Action Group. Diagnosis and treatment. Position paper July 2007. http:// www.bcagnsw.org.au/news.htm (accessed Jan 2012).

3 Caplan ES, Englander L, Hamzah E, et al. Bridging gaps, expanding outreach: Metastatic Breast Cancer Advocacy Working Group Consensus Report. January 25, 2008. Breast 2009; 18 : 273-275.

4 Coleman MP, Forman D, Bryant H, et al. Cancer survival in Australia, Canada, Denmark, Norway, Sweden, and the UK, 1995-2007 (the International Cancer Benchmarking Partnership): an analysis of population-based cancer registry data. Lancet 2011; 377: 127-138.

5 Jatoi I, Miller AB. Why is breast-cancer mortality declining? Lancet Oncol 2003; 4: 251-254.

6 Burton RC, Bell RJ, Thiagarajah G, Stevenson C. Adjuvant therapy, not mammographic screening accounts for most of the observed breast cancer specific mortality reductions in Australian women since the national screening program began in 1991. Breast Cancer Res Treat 2012; 131: 949-955.

7 Tracey E, Alam N, Chen W, Bishop J. Cancer in New South Wales: incidence and mortality 2006 Sydney: Cancer Institute NSW, 2008. http:// www.cancerinstitute.org.au/publications/i/ cancer-in-nsw-incidence-and-mortality-2006 (accessed May 2012)

8 Department of Health and Ageing. Measuring remoteness: accessibility/remoteness index of Australia (ARIA). Canberra: Commonwealth of Australia, 2001. http://www.health.gov.au/ internet/main/publishing.nsf/Content/healthhistoricpubs-hfsocc-ocpanew14a.htm (accessed May 2012).

9 Pink B. Socio-Economic Indexes for Areas (SEIFA) - Technical Paper, 2006. Canberra: Australian Bureau of Statistics, 2008. http://www.abs.gov. au/AUSSTATS/abs@.nsf/Lookup/2039.0.55.001 Main+Featuresl2006?OpenDocument (accessed May 2012)

10 Centre for Health Record Linkage. Quality assurance report 2011. http://www.cherel.org.au/ quality-assurance (accessed Mar 2012).

11 van den Hurk CJ, Eckel R, van de Poll-Franse LV, et al. Unfavourable pattern of metastases in $\mathrm{MO}$ breast cancer patients during 1978-2008: a population-based analysis of the Munich Cancer Registry. Breast Cancer Res Treat 2011; 128: 795-805.

12 Sateren WB, Trimble EL, Abrams J, et al. How sociodemographics, presence of oncology specialists, and hospital cancer programs affect accrual to cancer treatment trials. J Clin Oncol 2002; 20: 2109-2117.

13 YUXO, O'Connell DL, Gibberd RW, Armstrong BK. Assessing the impact of socio-economic status on cancer survival in New South Wales, Australia 1996-2001. Cancer Causes Control 2008; 19: 1383-1390.

14 Nixon AJ, Neuberg D, Hayes DF, et al. Relationship of patient age to pathologic features of the tumor and prognosis for patients with stage I or II breast cancer. J Clin Oncol 1994; 12: 888-894.

15 Fisher B, Dignam J, Wolmark N, et al. Tamoxifen and chemotherapy for lymph node-negative, estrogen receptor-positive breast cancer. J Natl Cancer Inst 1997; 89: 1673-1682.

16 Fisher B, Anderson S, Tan-Chiu E, et al. Tamoxifen and chemotherapy for axillary node-negative, estrogen receptor-negative breast cancer: findings from National Surgical Adjuvant Breast and Bowel Project B-23. J Clin Oncol 2001; 19: 931-942.

17 Mamounas EP, Bryant J, Lembersky B, et al. Paclitaxel after doxorubicin plus cyclophosphamide as adjuvant chemotherapy for node-positive breast cancer: results from NSABP B-28. J Clin Oncol 2005; 23: 3686-3696.

18 Martin M, Pienkowski T, Mackey J, et al; Breast Cancer International Research Group 001 Investigators. Adjuvant docetaxel for nodepositive breast cancer. NEngl J Med 2005; 352: 2302-2313.

19 Roché H, Fumoleau P, Spielmann M, et al. Sequential adjuvant epirubicin-based and docetaxel chemotherapy for node-positive breast cancer patients: the FNCLCC PACS 01 Trial. $J$ Clin Oncol 2006; 24: 5664-5671.

20 Saphner T, Tormey DC, Gray R. Annual hazard rates of recurrence for breast cancer after primary therapy. J Clin Oncol 1996; 14: 2738-2746.

21 Jatoi I, Tsimelzon A, Weiss H, et al. Hazard rates of recurrence following diagnosis of primary breast cancer. Breast Cancer Res Treat 2005; 89: 173-178.

22 Cuncins-Hearn AV, Boult M, Babidge W, et al. National breast cancer audit: overview of invasive breast cancer management. ANZ J Surg 2006; 76: 745-750.

23 Henderson T, Shepheard J, Sundararajan V. Quality of diagnosis and procedure coding in ICD-10 administrative data. Med Care 2006; 44: $1011-1019$.

24 Webster AC, Supramaniam R, O'Connell DL, et al. Validity of registry data: agreement between cancer records in an end-stage kidney disease registry (voluntary reporting) and a cancer register (statutory reporting). Nephrology (Carlton) 2010; 15: 491-501.

\section{Calling all general practice researchers and opinion leaders}

The MIA is open for business all year round. Rather than our yearly GP-themed issue, we are seeking to publish material relevant to general practice throughout the year. We want to host your best research, and to publish relevant comment on issues affecting general practice as they arise. Our call comes with a promise to prioritise excellent research, and to smooth the path to publication. 